\title{
Management of urethral strictures after masculinizing genital surgery in transgender men
}

\author{
Ariel Zisman, Joseph A. Baiocco, Rajveer S. Purohit \\ Department of Urology, Icahn School of Medicine at Mount Sinai Hospital, New York, NY 10075, USA. \\ Correspondence to: Dr. Ariel Zisman, Department of Urology, Icahn School of Medicine at Mount Sinai Hospital, 445 E. 77th \\ Street, New York, NY 10075, USA. E-mail: ariel.zisman@mountsinai.org \\ How to cite this article: Zisman A, Baiocco JA, Purohit RS. Management of urethral strictures after masculinizing genital surgery \\ in transgender men. Plast Aesthet Res 2022;9:15. https://dx.doi.org/10.20517/2347-9264.2021.113
}

Received: 8 Oct 2021 First Decision: 16 Dec 2021 Revised: 1 Jan 2022 Accepted: 17 Jan 2022 Published: 16 Feb 2022

Academic Editors: Stan Monstrey, ML Djordjevic Copy Editor: Xi-Jun Chen Production Editor: Xi-Jun Chen

\begin{abstract}
Transgender men undergoing phalloplasty and metoidioplasty have a high rate of urethral stricture. Evaluation of stricture includes evaluation of symptoms and uroflow, cystoscopy, and retrograde urethrogram. Important anatomic differences between the phallus of cis-gender and transgender men increase the likelihood and complexity of treating urethral strictures in transgender men after surgery. Urethral strictures after masculinizing procedures are more likely to require open surgical treatment and recur after treatment. There is a paucity of data, but less invasive options such as dilation and urethrotomy have had minimal success. Open surgical options with a variety of techniques, including one-stage and two-stage techniques, have higher success rates in treating strictures, but there is minimal comparative data on outcomes. We present a review on management options for urethral reconstruction in transgender men and our data on urethroplasty for these patients.
\end{abstract}

Keywords: Phalloplasty, urethroplasty, urethral stricture disease, gender-affirming surgery, metoidioplasty

\section{INTRODUCTION}

Phalloplasty and metoidioplasty are technically challenging masculinizing genital surgeries for transgender men. A metoidioplasty with urethral lengthening is a definitive option offering a sensate phallus and permitting urination while standing. For other men, the final end-point is a phalloplasty with urethral construction and with penile implants, one that permits penetrative intercourse. The creation of the 
neophallus with metoidioplasty and phalloplasty, however, is a complex procedure prone to urinary complications, including urethral stricture.

In the general population, the rate of urethral stricture disease can reach $0.6 \%$ and is more prevalent in patients older than 55 years old ${ }^{[1]}$. Both metoidioplasty and phalloplasty patients face a much higher risk of post-operative urethral stricture, ranging from $18 \%-58 \%^{[2-7]}$. After surgical treatment, they also have a higher rate for stricture recurrence than in cis-gender urethroplasty and may require multiple additional procedures.

The reasons for the high rate of stricture disease after metoidioplasty and phalloplasty are numerous and involve the complex anatomy of the neo-urethra. Current techniques of metoidioplasty with urethral lengthening carry a lower risk of strictures than phalloplasty ${ }^{[5]}$. Variations in phalloplasty type and surgical technique have also been shown to affect complication rates.

In this review, we will address the magnitude, etiology, treatment options and outcomes for urethral stricture disease after metoidioplasty and for phalloplasty in patients undergoing gender affirmation surgery and describe our experience with managing these complex patients.

\section{Differences in the urethral anatomy between cisgender and transgender men}

The anatomy of the neourethra includes the native urethra, the fixed part (pars fixa), anastomotic part, phallic part (pendulous urethra) and the meatus [Figure 1]. The most common sites for stricture are the anastomosis followed by the phallic urethra ${ }^{[8]}$. In contrast to cis-males, there are no corpora providing a rich vascularized bed for the neourethra or for any repair of the urethra. The healthy cis-gender urethral vascularity has significant redundancy and a rich network feeding the urethra from distal branches emanating from both the internal and the external iliac artery. In contrast, depending on the type of phalloplasty, the blood supply for the neourethra typically relies on a single vascular source or survival from the vascularity from adjacent tissue. Another consideration is that many patients desire a longer phallus which may result in longer segments of neo-urethra with a potentially increased risk of stricture disease.

Another factor absent in cis-gender men that can affect the neo-urethral flow dynamics is the presence of a vaginal remnant. This vagina-like tissue can remain or regrow after gender-affirming surgery in transmen who have had their vagina surgically removed and have had either inadequate resection of the vaginal tissue or stricture that increases pressure on the proximal urethra and causes one to enlarge. This remnant can be a source of infection, residual urine causing post-void dribbling and fistula.

\section{Metoidioplasty}

Metoidioplasty is one of the primary surgical options for creating a neophallus in male transgender patients. A hypertrophied clitoris after systemic testosterone therapy is utilized for the creation of the neophallus, and the urethra is tubularized, typically using local flaps alone or augmenting them with free grafts. Metoidioplasty permits urination while standing but does not allow for penetration during intercourse in most patients. Hage and van Turnhout ${ }^{[9]}$ presented in 2006 the first long-term outcome for a series of 70 patients undergoing metoidioplasty. Complication rates were high, including 35\% urethral stricture rate and $37 \%$ fistula rates ${ }^{[9]}$. Djordjevic et al. ${ }^{[5]}$ reported their outcome of a single-stage metoidioplasty with urethral lengthening with combined buccal mucosa graft and local genital skin flaps. They reported only 2 cases (2.4\%) of urethral strictures and 7 cases $(8.5 \%)$ of urethral fistulas that required surgery ${ }^{[5]}$. 


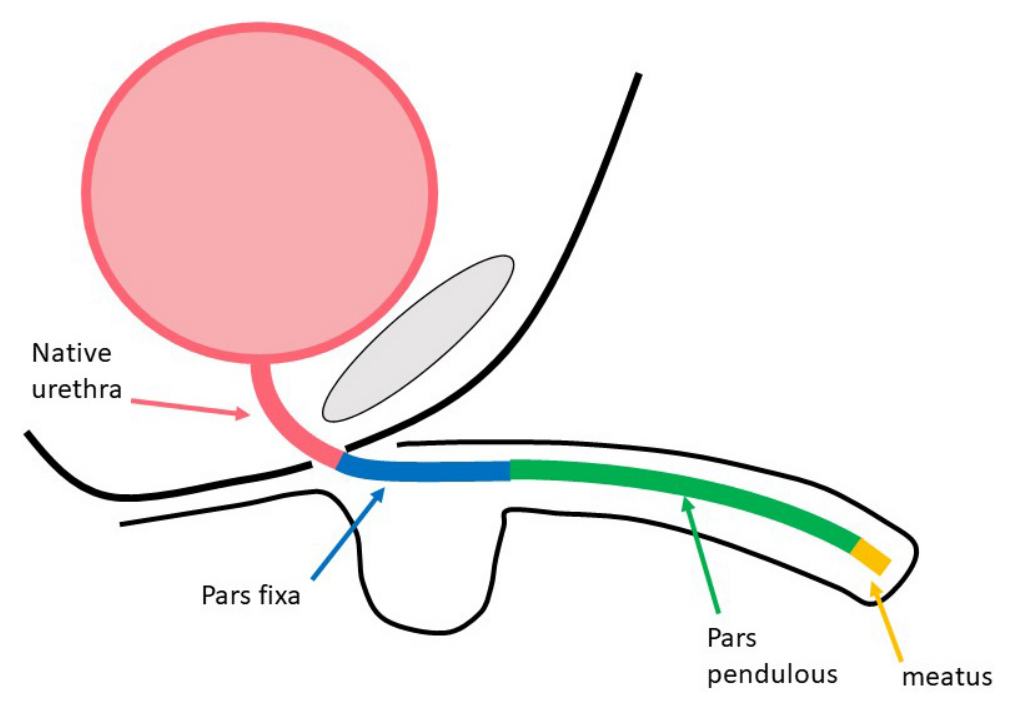

Figure 1. Neo-phallus urethra illustrated with native urethra, pars fixa, pars pendulous, and meatus.

\section{Techniques in phalloplasty and urethral construction}

The urethra is constructed in different ways with different phalloplasty techniques [Table 1]. One option, includes construction of the urethra at the time of the phalloplasty typically occurs during the radial forearm free flap phalloplasty (RFFF) and the anterior lateral thigh flap (ALT) phalloplasty. The second option for construction of the urethra with the phalloplasty is in a staged fashion which occurs with the abdominal phalloplasty, the musculocutaneous latissimus dorsi (MLD) phalloplasty and others such as the Superficial circumflex iliac artery perforator flap. These can impact the type and location of the stricture.

\section{Tube within tube techniques}

RFFF is the most commonly utilized surgical technique for phalloplasty ${ }^{[10]}$. Advantages of the RFFF include a thin flap and relatively skinless ulnar surface for construction of the urethra using the tube within a tube one-stage technique. Nonetheless, the patient is left with a visible scar on his forearm and a scar from the skin donor site to cover the forearm scar. Monstrey et al. ${ }^{[2]}$ described a series of 287 patients using a onestage RFFF technique for all patients. The overall rate of urethral stricture or fistula requiring urethroplasty was $18 \%$. The RFFF utilizes the radial artery with its venae comitantes and the cephalic vein for urethral vascularity. Typically, this anastomosis is formed at the proximal portion of the neo-phallic urethra. One might expect to find a higher incidence of the strictures in the distal edges of this pedicle.

Though not common, the urethra can be constructed using a radial artery-based forearm free flap urethroplasty. Garaffa et al. ${ }^{[11]}$ reported their experience for a two-stage procedure where they reconstructed a neo-urethra from RFFF, and incorporated it in a previously constructed pedicled pubic phalloplasty. This technique resulted in $4 \%$ stricture rate and $5 \%$ fistula rate in 27 patients.

Salgado et al. ${ }^{[12]}$ reported their outcome on a series of 21 transgender male patients undergoing two-stage radial forearm phalloplasty, using a flap neourethra prelamination with buccal, vaginal, or uterine mucosa. The urethral stricture rate was $19 \%$.

ALT (Anterior lateral thigh flap) is another tube-within-a-tube technique commonly used for phalloplasty. In comparison with the RFFF, the main advantages are a less clearly visible donor site scar and a neophallus with a skin color more resembling the groin area. Ascha et al. ${ }^{[3]}$ reported a $21 \%$ incidence of urethral 
Table 1. Phalloplasty types and reported rates of urethral stricture

\begin{tabular}{|c|c|c|c|}
\hline Flap type & Technique & Vascular blood supply & Reported rate of urethral stricture \\
\hline $\operatorname{RFFF}^{[2,6,7]}$ & Tube within tube & Radial artery & $18 \%-58 \%$ \\
\hline $\mathrm{ALT}^{[3]}$ & Tube within tube & $\begin{array}{l}\text { Branch of lateral femoral } \\
\text { circumflex artery }\end{array}$ & $21 \%$ \\
\hline Abdominal phalloplasty ${ }^{[4]}$ & One or two stage & Superficial Epigastric artery & $44 \%-94 \%$ \\
\hline$M L D^{[13]}$ & Two stage & thoracodorsal vascular bundle & $25 \%$ \\
\hline
\end{tabular}

RFFF: Radial forearm free flap phalloplasty; ALT: anterior lateral thigh flap; MLD: musculocutaneous latissimus dorsi flap.

stricture among 64 patients who underwent a single-stage ALT. Total urethral complications, including meatal stenosis and fistulas were $32.8 \%$.

Phalloplasty without concomitant urethral construction

Abdominal phalloplasty typically uses a tubularized segment of subcutaneous tissue from the anterior abdominal wall to construct the neo-phallus. Bettocchi et al. ${ }^{[4]}$ published their experience with 80 patients undergoing phalloplasty using a flap of anterior abdominal wall skin, while constructing the neourethra with skin from the clitoris and labia majora. Out of which, 32 patients underwent a 1-stage procedure, and 48 had a 2-stage procedure. In the 2-stage technique, neourethra was fashioned after the neophallus had been given time to heal. The total urethral stricture rate was very high, but even significantly higher in the 1stage than the 2 -stage technique ( $94 \% v s .44 \%)$. The authors reported transitioning from 1-stage to 2 -stage technique due to the high rate of complications in the 1-stage procedure ${ }^{[4]}$.

MLD phalloplasty relies on a flap whose blood supply originates from the thoracodorsal vascular bundle. Djordjevic et al ${ }^{\left[{ }^{[13]}\right.}$ reported the largest experience in a series of 129 patients. In the first stage of urethral reconstruction after the MLD, local flaps including from the labia or from tissue available from a metoidioplasty were used to lengthen the urethra to reach the middle of the neophallus, and in the second stage, buccal mucosa was used to lengthen the urethra distally. Thirty-three patients (25\%) developed urethral stricture that required dilation or surgical revision.

\section{EVALUATION OF NEO-PHALLIC STRICTURES}

\section{Symptoms}

Patients with neo-phallic strictures typically present with worsened storage symptoms, including urinary urgency and frequency as well as increasing voiding symptoms such as slowed urinary stream, which can be assessed by uroflow and post-void dribbling. In addition, patients may report recurrent urinary infections, retain urine, have a urethrocutaneous fistula from increased proximal pressure on the urethra [Figure 2], and/or a sizable vaginal remnant. In terms of patient reported outcomes, there is a lack of data and great variability between patients in terms of symptoms and needs for additional intervention.

Cystoscopy can help diagnose the stricture, but utility may be limited by the inability of the cystoscope to pass through the distal-most extent of the stricture. Because of this, to evaluate the urethra proximal to the stricture or the presence of complicating factors such as a fistula or vaginal remnant, we have found a retrograde urethrogram (RUG) and/or voiding cystourethrogram to be critical prior to corrective surgery. The length, location, density of the stricture as well as the presence of complicating factors such as vaginal remnant can usually be determined from the RUG. Ideally, this should be done by the surgeon who is most aware of the important pre-operative questions that need to be answered [Figure 3]. 

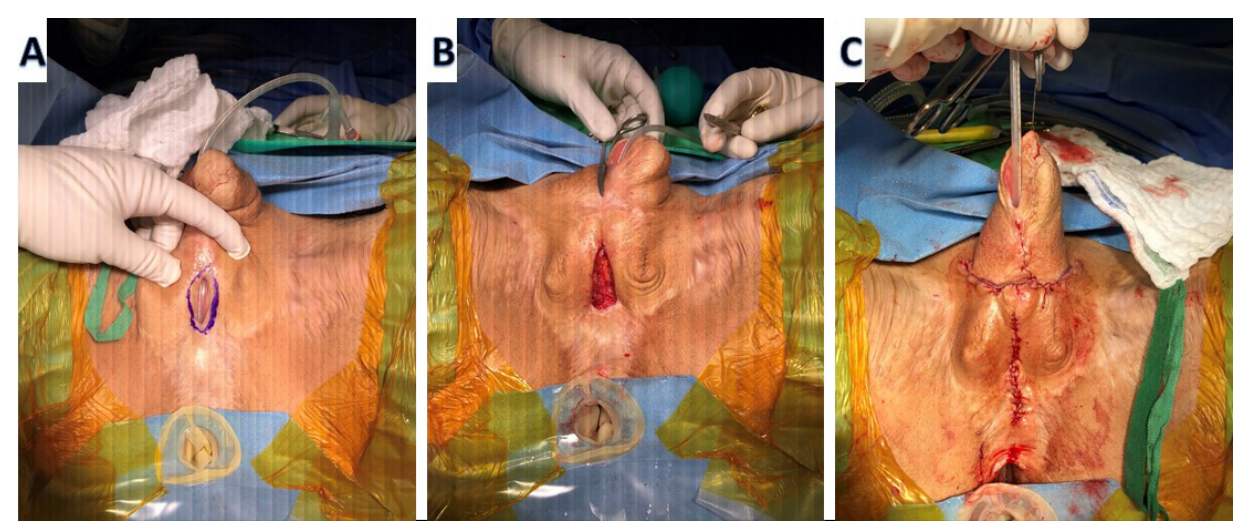

Figure 2. Urethral fistula and Pars fixa urethral stricture repair with local skin flap. (A) Fistula site marked. (B) Incision of fistula and stricture. (C) Phallus after repair.

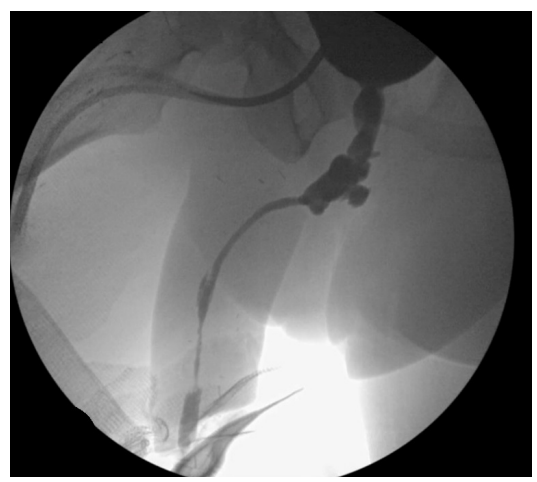

Figure 3. Post-phalloplasty pendulos pan-urethral stricture on retrograde urethrogram (RUG).

\section{MANAGEMENT OF NEO-PHALLIC STRICTURES}

\section{Urethral dilation}

A variety of techniques can be utilized to dilate a urethral stricture after both phalloplasty and metoidioplasty. These techniques include placement of progressive larger sounds in the urethra, placement of urethral balloon which is inflated at the site of a stricture, placement of a guidewire with progressively larger sounds and/or a filiform and progressively larger followers. Clean intermittent catheterization (CIC) has been utilized in an attempt to maintain urethral patency and effectively form repeated urethral dilations.

Internal urethrotomy can be accomplished with either a cold knife or a laser and with or without concomitant steroids. Use of concomitant local corticosteroids injection into the stricture has been advocated to prevent recurrence in cis-gender urethral strictures but has not shown significant efficacy ${ }^{[14]}$ and has not been evaluated in the transgender population.

There is very little data on the use of dilations or urethrotomy for urethral stricture in the neo-phallus. Repeat dilations in the cis-gender population have been shown to be ineffective. Because the majority of neo-phallic strictures occur from ischemic phenomenon, there is little reason to suspect that dilations are an effective or curative form of treatment in this population. Direct vision internal urethrotomy has poor results in neophallic stricture disease with failure rates of $87 \%^{[15]}$. 
Urethral dilation, CIC or internal urethrotomy may be considered as an option for patients who do not want or are not candidates for more definitive treatment with the understanding that there may be a higher failure rate than reconstructive options. However, complex false passages and long-term worsening of their strictures after repeated dilations may occur. For this reason, we rarely perform repeat dilations, urethrotomy or recommend CIC without first offering urethroplasty as a more definitive option.

\section{Urethral reconstruction for metoidioplasty strictures}

Repair of metoidioplasty strictures has not been well described in the literature. Depending on the location and the length of the stricture, we prefer to repair them in either one stage or two stages using buccal mucosal grafts [Figures 4 and 5]. Local skin flaps may also be an option, but the vascularity of the skin flap can be unpredictable. Similar to cisgender patients' urethroplasty, for short strictures $(<2 \mathrm{~cm})$, we prefer to repair in one stage using a buccal mucosal graft or a Heineke-Mikulicz nontransecting urethroplasty. For longer strictures $(>2 \mathrm{~cm})$, we repair them in two stages in a Bracka style repair with the first stage involving placement of buccal mucosal grafts. We wait until the graft and adjoining tissue is soft and supple, which typically takes six months and then tubularize the urethral plate in the second stage ${ }^{[16]}$. At this time adjacent vascularized tissue can be used to provide tissue coverage to minimize the risk of fistula. Occasionally, residual vaginal remnant may be present, and this can provide additional flap tissue for a urethroplasty.

\section{Urethral reconstruction for strictures after phalloplasty}

Open surgical treatment options for neo-phallic strictures can be divided into single-stage $v$ s. staged repairs.

\section{Single-stage repairs}

Nontransecting urethroplasty, based on the Heineke-Mikulicz surgical principle for stricturoplasty, can be used for short $(<1 \mathrm{~cm})$ strictures in cis-male patients. With this technique, a longitudinal incision is made through the ventral aspect of the stricture and then closed with interrupted sutures horizontally. This technique is typically used for short, non-dense stricture ${ }^{[8]}$ and confers the benefit of preserving any residual vascularity.

Excision and primary anastomotic (EPA) urethroplasty involves excision of the fibrotic stricture and anastomosing the better vascularized proximal and distal segments of the urethra. EPA can have a high success rate in cis-gender patients, but there is little data on its use in the transgender population ${ }^{[17]}$. Verla et al.$^{[18]}$ had $43 \%$ failure rate in a series of 44 patients. We reserve this option for patients with short and dense strictures ${ }^{[8]}$. These patients should have a segment of the urethra that can be mobilized proximal and distal to the stricture without compromising the appearing of the phallus. The SPY Portable Handheld Imager (SPY-PHI) is a handheld instrument that uses fluorescence Imaging technology in combination with indocyanine green to check for adequate tissue vascularity in reconstructive surgery. The use of the SPY imaging system can augment intra-operative visualization of the viability of the transected urethral ends.

Another option is the use of local skin flaps for reconstruction of the urethra. Because of the unpredictability of the vascular supply of the local skin, we do not routinely use this option for patients.

Among cis-male patients, complex urethral reconstruction is mostly performed with oral buccal mucosal grafts (BMG). The reason for the wide acceptance of BMG as graft tissue to fix urethral stricture disease is due to its inherent properties which include: readily availability, a concealed donor site, a non-keratinized elastic epithelium with rich pan-laminar vascular plexus, which normally resides in moist surroundings and is resistant to skin infections ${ }^{[19]}$. 

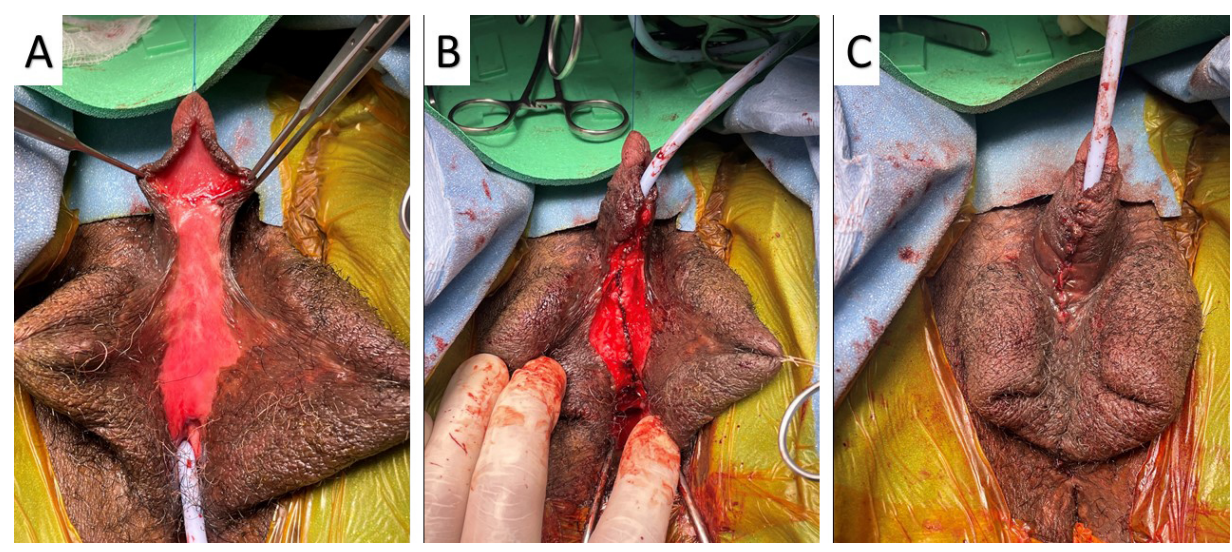

Figure 4. Two-stage repair of Metoidioplasty urethral stricture. (A) BMG 6 months after the first stage urethroplasty. (B) Neo-urethra tubularized over catheter. (C) Metoidioplasty after repair. BMG: Buccal mucosal grafts.
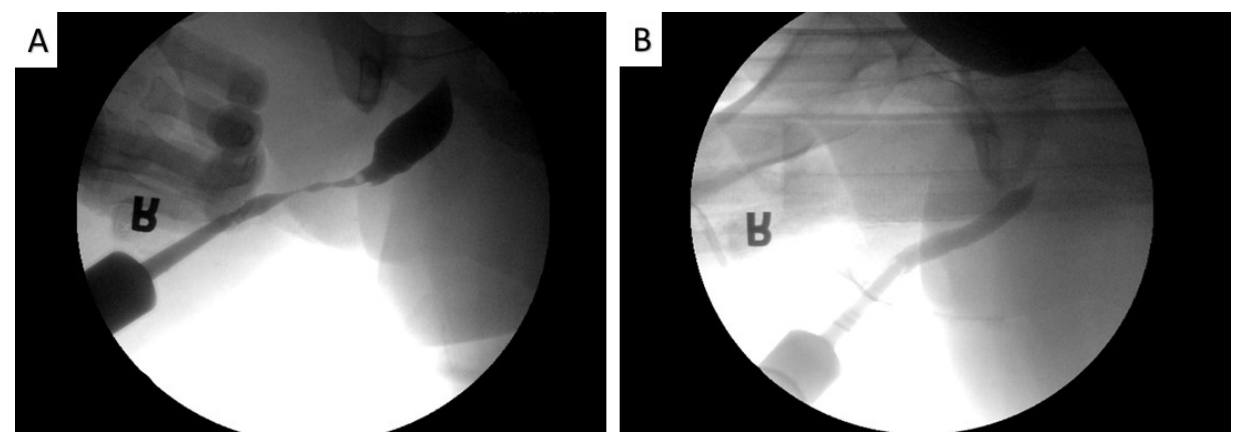

Figure 5. RUG images of metoidioplasty stricture repair. (A) Neo-urethral stricture. (B) Post urethroplasty image. RUG: Retrograde urethrogram.

One stage substitution urethroplasty can also be used for transgender men with neo-phallic strictures. One stage repairs with BMG can be performed in a variety of ways, including using the graft as a dorsal inlay urethroplasty, ventral onlay urethroplasty or a combined dorsal inlay and ventral onlay graft urethroplasty.

In dorsal inlay urethroplasty using BMG (Asopa technique), a ventral longitudinal midline urethrotomy is made to expose the stricture and a dorsal urethrotomy and mucosal planes developed. The BMG is quilted and anastomosed to the dorsal urethral plate in an inlay fashion. In dorsal onlay urethroplasty the urethra is dissected free from the underlying tissues and a urethrotomy is performed. The BMG is then sutured to the dorsal urethra with the expectation that the underlying dorsal tissue has a rich enough vascularity to maintain the graft.

Ventral onlay techniques involve performing a ventral urethrotomy followed by augmentation with BMG ventrally. In cisgender patients, the ventral component may be supported by adjacent vascularized tissue, but the use of these techniques is challenging in transgender patients due to poor vascular bed and scar tissue in the neophallus. Optimal techniques in single-stage urethroplasty after phalloplasty are not well described but failure rates are high with single-staged techniques with up to $40 \%-50 \%$ with recurrent stricture. Combination techniques can also be used in a single stage. Beamer et al. ${ }^{[20]}$ has noted improved results for a single-staged technique combining dorsal inlay and ventral onlay BMG urethroplasty. With 1year follow up, they reported an $80 \%$ success rate for transgender patients treated with phalloplasty strictures. 


\section{Staged repairs}

Staged urethral repairs in cis-male patients are needed in case of complex cases such as long strictures, prior failed attempts, lichen sclerosis or failed hypospadias surgery. It is based on Bracka's technique for two-stage hypospadias surgery ${ }^{[16]}$. In the first stage, following ventral urethrotomy, the strictured segment of the urethra is incised or excised and a neo-urethral plate is constructed using a graft - typically a BMG. The patient will void through a proximal urethrostomy for about six months until the second stage. This period of time will give the neo-urethra and graft time to develop neo-vascularity. In the second stage, the neourethral plate graft edges will be tabularized [Figure 6]. Lumen et al. ${ }^{[8]}$ described that staged repair urethroplasty is superior to non-staged repair urethroplasty for stricture disease after phalloplasty.

\section{Perineal urethrostomy}

The creation of a perineal urethrostomy may be an option for patients who have failed multiple attempts at stricture repair and/or who want the procedure with the highest chance for success. In addition, the perineal urethrostomy may be a temporary or permanent option for transgender men in whom standing to void is not bothersome, men with significant co-morbidities or those with co-existing conditions such as infections that preclude complex reconstruction. We perform a modification of the Blandy inverted U-shape flap with a midline anterior extension. If a vaginal remnant is present, it can be removed concurrently. We have found that patients who undergo a perineal urethrostomy have significantly improved quality of life after surgery.

\section{OUR EXPERIENCE}

We retrospectively evaluated our experience with urethral reconstructive surgery performed for stricture disease in transgender men after phalloplasty. Treatment outcome was evaluated on follow-up using cystoscopy or retrograde urethrogram. Treatment failure was defined by the recurrence of stricture or fistula requiring additional reconstructive surgery. We performed 18 reconstructive surgeries for 14 transgender men after phalloplasty from March 2018 to February 2021 at our institution. Median patient age was 42 years (26-64 years). Surgeries included one-stage or staged urethroplasty $(n=11)$, perineal urethrostomy as temporary or definitive treatment $(n=5)$ and DVIU in 2 patients [Table 2]. Of those undergoing urethroplasty, 3 patients underwent staged urethroplasty using BMG and 8 underwent nonstaged ventral onlay urethroplasty ( 6 with local vaginal flap and 2 using BMG). The median time to reconstructive procedure from initial phalloplasty was 15.7 months. At a median follow up of 8 months, 5 urethroplasty procedures had failed (45\%). The median time from treatment to failure was 6.3 months. Because this is a relatively small cohort of patients, it was difficult to assess for statistical significance. Future research with larger sample size is needed.

Lessons learned given our experience:

1. Repair of transgender patients' strictures has a higher recurrence rate than that of cisgenders' strictures.

2. A perineal urethrostomy may be an option for patients with recurrent strictures.

3. Staged repairs may be considered for more complex strictures.

\section{CONCLUSION}

There is significant risk for urethral stricture and fistula after metoidioplasty and phalloplasty. There is an absence of long-term quality data on optimal techniques to manage this. Urethral dilation and internal urethrotomy are prone to failure. Urethroplasty after phalloplasty or metoidioplasty is a challenging 
Table 2. Our single center experience with transgender urethral stricture disease

\begin{tabular}{|c|c|c|c|c|c|c|}
\hline Procedure & $\begin{array}{l}\text { One stage urethroplasty } \\
\text { with local skin flap }\end{array}$ & $\begin{array}{l}\text { One stage } \\
\text { urethroplasty with } \\
\text { BMG }\end{array}$ & $\begin{array}{l}\text { Staged urethroplasty } \\
\text { with BMG }\end{array}$ & DVIU & $\begin{array}{l}\text { Perineal } \\
\text { urethrostomy }\end{array}$ & Total \\
\hline Number (\%) & $6(33 \%)$ & $2(11 \%)$ & $3(16 \%)$ & $\begin{array}{l}2 \\
(11 \%)\end{array}$ & $5(27 \%)$ & 18 \\
\hline Failures n (\%) & $2(33 \%)$ & $1(50 \%)$ & $2(66 \%)$ & $\begin{array}{l}1 \\
(50 \%)\end{array}$ & 0 & 7 \\
\hline
\end{tabular}

BMG: Buccal mucosa graft; DVIU: direct vision internal urethrotomy.
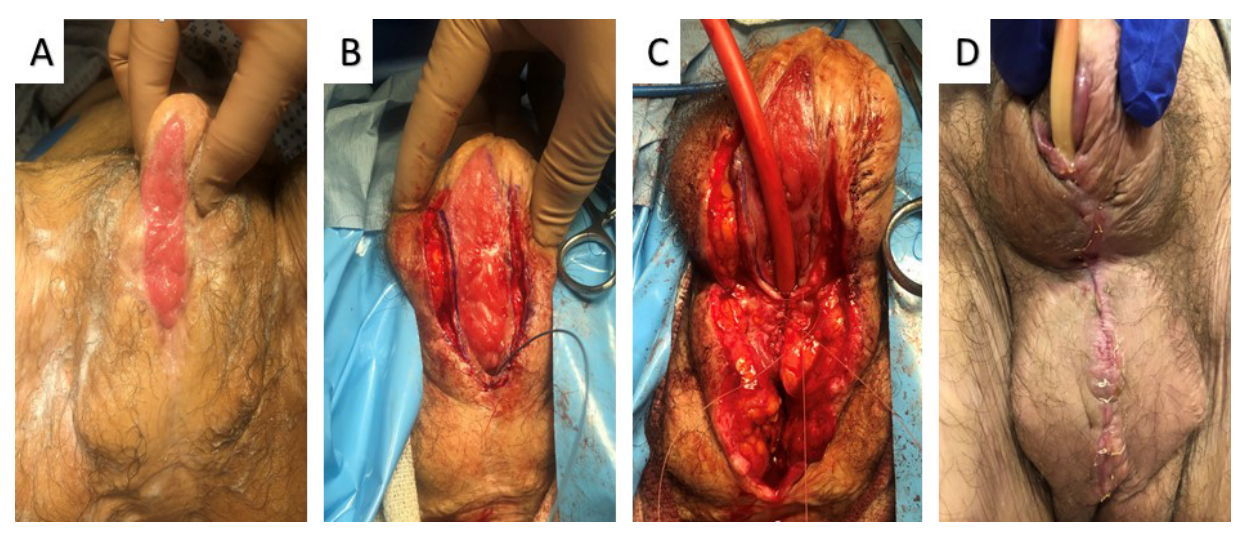

Figure 6. Second stage urethral stricture repair using BMG for abdominal phalloplasty. (A) Buccal mucosa graft 6 months after the first surgery. (B) Dissection of the lateral edges of the BMG. (C) Neo-urethral tabularization over catheter. (D) Phallos after repair. BMG: Buccal mucosal grafts.

procedure that may require multiple surgeries. Perineal urethrostomy may be a salvage option for patients who have undergone multiple failed prior attempts at repair.

\section{DECLARATIONS}

\section{Authors' contributions}

Made substantial contributions to conception and design of the study and performed data analysis and interpretation: Zisman A, Baiocco JA, Purohit RS

Performed data acquisition, as well as provided administrative, technical, and material support: Zisman A, Baiocco JA, Purohit RS

Provided the figures: Purohit RS

Availability of data and materials

Not applicable.

\section{Financial support and sponsorship}

None.

\section{Conflicts of interest}

All authors declared that there are no conflicts of interest.

\section{Ethical approval and consent to participate}

IRB research number: STUDY-20-01505. 


\section{Consent for publication}

Not applicable.

\section{Copyright}

(c) The Author(s) 2022.

\section{REFERENCES}

1. Santucci RA, Joyce GF, Wise M. Male urethral stricture disease. J Urol 2007;177:1667-74. DOI PubMed

2. Monstrey S, Hoebeke P, Selvaggi G, et al. Penile reconstruction: is the radial forearm flap really the standard technique? Plast Reconstr Surg 2009;124:510-8. DOI PubMed

3. Ascha M, Massie JP, Morrison SD, Crane CN, Chen ML. Outcomes of single stage phalloplasty by pedicled anterolateral thigh flap versus radial forearm free flap in gender confirming surgery. J Urol 2018;199:206-14. DOI PubMed

4. Bettocchi C, Ralph DJ, Pryor JP. Pedicled pubic phalloplasty in females with gender dysphoria. BJU Int 2005;95:120-4. DOI PubMed

5. Djordjevic ML, Stanojevic D, Bizic M, et al. Metoidioplasty as a single stage sex reassignment surgery in female transsexuals: Belgrade experience. J Sex Med 2009;6:1306-13. DOI PubMed

6. Doornaert M, Hoebeke P, Ceulemans P, T'Sjoen G, Heylens G, Monstrey S. Penile reconstruction with the radial forearm flap: an update. Handchir Mikrochir Plast Chir 2011;43:208-14. DOI PubMed

7. Rohrmann D, Jakse G. Urethroplasty in female-to-male transsexuals. Eur Urol 2003;44:611-4. DOI PubMed

8. Lumen N, Monstrey S, Goessaert AS, Oosterlinck W, Hoebeke P. Urethroplasty for strictures after phallic reconstruction: a singleinstitution experience. Eur Urol 2011;60:150-8. DOI PubMed

9. Hage JJ, van Turnhout AA. Long-term outcome of metaidoioplasty in 70 female-to-male transsexuals. Ann Plast Surg 2006;57:312-6. DOI PubMed

10. Rooker SA, Vyas KS, DiFilippo EC, Nolan IT, Morrison SD, Santucci RA. The rise of the neophallus: a systematic review of penile prosthetic outcomes and complications in gender-affirming surgery. J Sex Med 2019;16:661-72. DOI PubMed

11. Garaffa G, Ralph DJ, Christopher N. Total urethral construction with the radial artery-based forearm free flap in the transsexual. BJU Int 2010;106:1206-10. DOI PubMed

12. Salgado CJ, Nugent A, Hadeed J, et al. Two-stage prelaminated mucosal neourethra radial forearm flap phalloplasty for transgender men. Glob J Med Res 2021;1:1-3. DOI

13. Djordjevic ML, Bencic M, Kojovic V, et al. Musculocutaneous latissimus dorsi flap for phalloplasty in female to male gender affirmation surgery. World J Urol 2019;37:631-7. DOI PubMed

14. Yildirım ME, Kaynar M, Ozyuvali E, et al. The effectiveness of local steroid injection after internal urethrotomy to avoid recurrence. Arch Ital Urol Androl 2016;87:295-8. DOI PubMed

15. Levine LA, Elterman L. Urethroplasty following total phallic reconstruction. J Urol 1998;160:378-82. PubMed

16. Bracka A. A versatile two-stage hypospadias repair. Br J Plast Surg 1995;48:345-52. DOI PubMed

17. Santucci RA, Mario LA, Aninch JWMC. Anastomotic urethroplasty for bulbar urethral stricture: analysis of 168 patients. $J$ Urol 2002;167:1715-9. PubMed

18. Verla W, Hoebeke P, Spinoit AF, Waterloos M, Monstrey S, Lumen N. Excision and primary anastomosis for isolated, short, anastomotic strictures in transmen. Plast Reconstr Surg Glob Open 2020;8:e2641. DOI PubMed PMC

19. Markiewicz MR, Margarone JE, Barbagli G, Scannapieco FA. Oral mucosa harvest: an overview of anatomic and biologic considerations. EAU-EBU Update Series 2007;5:179-87. DOI

20. Beamer MR, Schardein J, Shakir N, et al. One or two stage buccal augmented urethroplasty has a high success rate in treating post phalloplasty anastomotic urethral stricture. Urology 2021;156:271-8. DOI PubMed 